Res Publica. Revista de Historia de las Ideas Políticas ISSN: 1576-4184

http://dx.doi.org/10.5209/RPUB.56475

\title{
Dominar, proteger, crear. Un ensayo filosófico sobre las actitudes utópicas ante la naturaleza*
}

\author{
Francisco Martorell Campos**; Andoni Alonso***
}

Recibido: 23 de febrero de 2017 / Aceptado: 10 de mayo de 2017

Resumen: La cuestión medioambiental acapara cada día la atención internacional y condiciona en buena medida las fantasías condenatorias de la sociedad actual. Persistentemente se nos anuncian finales del mundo y escenarios apocalípticos brotados de la venganza de la naturaleza, víctima, se cuenta, del progreso irresponsable y devastador del ser humano. En este artículo pretendemos reflexionar filosóficamente en torno a los impactos de la acción humana sobre el mundo físico adoptando como objeto de estudio las actitudes de la utopía ante la naturaleza. Nuestra intención principal es la de sugerir una aproximación utopista a los problemas ecológicos que haga frente, por igual, a las contraindicaciones de las utopías tradicionales, a la condena antiutópica de las alternativas políticas, a las soluciones institucionales basadas en la sostenibilidad y a los pavores de la ecología del miedo. De paso, esperamos aclarar las diferencias ontológicas entre la utopía moderna y la utopía postmoderna, así como reivindicar la necesidad y viabilidad de un nuevo utopismo.

Palabras clave: Utopía; distopía; naturaleza; tecnología; ecología; medioambiente.

\section{[en] Dominating, Protecting, Creating. A Philosophical Essay about Utopianist Attitudes}

\begin{abstract}
Environmental issues captures international attention in a daily base and shapes in a great extent the fantasies of contemporary society about an imminent Apocalypse. Again and again the end of the world is announced coupled with apocalyptic settings based in a Nature's revenge for being victim of the irresponsible and devastating human progress. Our aim is to propose a utopian approach to environmental crisis to cope with the following issues: counter-instructions from classical utopias, anti-utopian claims against political alternatives, institutional solutions based on sustainability and paralyzing fears from a frightening ecologism. Also, we will try to elucidate ontological differences between Modern and Post-Modern utopia, reclaiming the need and feasibility of a new utopianism.
\end{abstract}

Keywords: Utopia; Dystopia; Nature; Technology; Ecology; Environment.

Sumario: 0. Introducción. 1. Dominar a la naturaleza. 2. Proteger a la naturaleza I: La utopía del campo. 3. Proteger a la naturaleza II: La distopía. 4. Crear a la naturaleza I. 5. Crear a la naturaleza II. 6. A modo de conclusión: Trascender a la naturaleza.

\footnotetext{
* Este trabajo se ha realizado en el marco del proyecto Historia del futuro: la utopía y sus alternativas en los horizontes de expectativa del mundo contemporáneo. Siglos XIX-XXI (HAR2015-65957-P) del Plan Nacional de $\mathrm{I}+\mathrm{D}+\mathrm{i}$ del Gobierno de España.

** Universitat de València Francisco.Martorell@uv.es

*** $\quad$ Universidad Complutense de Madrid andonial@ucm.es
} 
Cómo citar: Martorell Campos, F; Alonso, A. (2017). Dominar, proteger, crear. Un ensayo filosófico sobre las actitudes utópicas ante la naturaleza, en Res publica 20.2,357-376.

\section{Introducción}

Hace apenas unos meses se celebró en Marrakech la última Cumbre del Clima. El evento remacha por ahora una sucesión de cónclaves internacionales de dudosísima eficacia en cuyos aledaños suelen acampar miles de activistas para reivindicar a las autoridades gubernamentales allí congregadas la promulgación de acuerdos medioambientales verdaderamente vinculantes. Esta instantánea recoge una de las secuencias definitorias de nuestros días, a saber: la instauración del cuidado de la naturaleza en objeto central de los discursos públicos oficiales y extraoficiales con el telón de fondo de la extinción humana. En el presente trabajo queremos interpretar y valorar dicha circunstancia adoptando como marco de referencia las actitudes desprendidas del encuentro entre la utopía y la naturaleza a lo largo del tiempo. Puesto que nos encontramos con una relación firmemente mediada por la tecnología, será labor nuestra determinar de igual forma el papel que ha cumplido en los heterogéneos paradigmas utópicos. El objetivo rector que nos marcamos es doble. Por un lado, moldear teóricamente una nueva actitud utopista y por consiguiente hiperpolítica ante los retos ecológicos sin caer en la trampa del bucolismo arcádico — restaurar la vida aldeana, sencilla, artesanal- y de la sostenibilidad — reducir emisiones sin modificar el sistema. Por otro, rebatir algunos supuestos metafísicos de las utopías modernas sin caer en la trampa de la antiutopía, esto es, en la condena de cualquier alternativa emancipadora con el pretexto de que los hechos históricos demuestran que ya vivimos en el mejor o menos malo de los mundos posibles.

García Bacca brindó en Elogio de la técnica material idóneo para iniciar la reflexión. De acuerdo con su perspectiva, el maridaje hombre-naturaleza atraviesa tres etapas dialécticas de gradual desalienación condicionadas por el tipo de tecnología preponderante en cada lapso. La primera acoge a la naturaleza Creadora y al "hombre primitivo", mera creatura que blande una técnica aristotélica, sometida a los fines impuestos por lo natural. En la segunda, la naturaleza deviene sierva del "hombre primero", erigido en Señor de lo natural merced a una técnica naturalista que descubre, humaniza y somete a la naturaleza. Finalmente, la naturaleza muta en creatura del "hombre primario", hecho a sí mismo Creador gracias a una técnica supernatural que descalifica y trasciende a la naturaleza.

Nuestra tesis es que el paso de la segunda a la tercera etapa ejemplifica en la esfera ontológica el paso de la modernidad a la postmodernidad y en la esfera utopista el paso de la utopía moderna estándar a la postmoderna estándar. Según veremos, tratamos con dos actitudes utópicas discordantes. Si otrora la utopía supeditó parte de la emancipación humana al dominio tecnológico de la naturaleza, hoy hace lo propio con la creación tecnológica de la naturaleza. Si bien es cierto que en bastantes utopías modernas ya se vislumbraban gestos típicos del estadio de la creación, será en las utopías postmodernas donde el creacionismo adquiera conciencia de sí mismo y se explicite sistemáticamente. Contra ambos modelos utópicos, inequívocamente urbanos, antropocéntricos, humanistas y cientificistas, adversos por motivos distin-

G. Bacca, Elogio de la técnica, Barcelona, Anthropos, 1987, pp. 73-74. 
tos al arquetipo de la naturaleza-natural, se levantarán la utopía del campo y la distopía, próximas al estadio de subordinación a lo natural con el que arranca la trama episódica de Bacca.

Puesto que manejamos conceptos muy generales y polisémicos, nos vemos obligados a definirlos. Las próximas páginas versarán únicamente sobre la noción que la metafísica nos ha legado de la naturaleza externa, asociada, casi sin excepciones, a un mundo dado, ancestral y primigenio, independiente y diferente del hombre, de las representaciones, del lenguaje y de la sociedad, hecho a sí mismo y autorregulado; un mundo, en suma, convertido en condición de posibilidad de multitud de dualismos y antinomias. En lo tocante a la utopía, nos ceñiremos al contenido y a la intención de sus manifestaciones textuales, sean literarias o filosóficas, eutópicas o distópicas, dando por entendido que amén de diagnosticar los males sociales reflejan sintomáticamente los deseos y temores más avanzados de la época a la que desafían.

El guion al que nos vamos a ceñir es el siguiente. Empezaremos (1) explorando la actitud utópica ante la naturaleza típica de la modernidad, basada en la estigmatización y en el dominio del mundo no-humano al margen de cualquier conciencia o consideración medioambiental. Después, ilustraremos cómo la explotación baconiana de lo natural sufre la censura de (2) las utopías del campo y de (3) las distopías, estandartes de la protección de la naturaleza que adquirirán la mayoría de edad ecologista en la década de los setenta del siglo XX. Posteriormente, inspeccionaremos (4) el cuestionamiento material y conceptual de la naturaleza a manos de dispares frentes teóricos actuales, para pasar después (5) a la inspección de la utopía postmoderna estándar, articulada alrededor del fin de la naturaleza-natural y de la creación tecnológica de la naturaleza-artificial. Finalmente (6), procuraremos justificar con argumentos pragmatistas y a la luz de los objetivos anteriormente indicados la conveniencia de que la utopía prescinda del término "naturaleza".

\section{Dominar a la naturaleza}

Según Jameson ${ }^{2}$, el grueso de la tradición utópica se concentra en torno al enfrentamiento entre la utopía urbana y la utopía del campo. Mientras la primera personifica el espíritu racionalista, industrialista, ilustrado, materialista y utilitarista de la conciencia moderna, la segunda alza una alternativa romántica, vitalista y ruralista. De ahí que sea la utopía urbana quien detente el papel de utopía estándar — esto es, paradigmática y prototípica - de la modernidad, reservándose a la utopía campestre el papel, indiscutiblemente señalado, de reaccionar contra los planes concebidos con antelación por aquella. No en vano, la utopía siempre gira alrededor de la ciudad, incluso cuando esgrimiendo las presuntas virtudes de la vida rural se atacan o denuncian sus males. Nada extraño, habida cuenta de que el nacimiento oficial de la utopía coincide con el auge de la vida urbana y el declive de la vida rural impulsados por el entonces flamante capitalismo.

La disyuntiva topográfica ciudad-campo puede traducirse filosóficamente en la disyuntiva ontológica que enfrenta a lo artificial y a lo natural. Enfocando la cuestión desde este ángulo, se hace evidente el empaque positivista y esencialista del

F. Jameson, Las semillas del tiempo, Madrid, Trotta, 2000, p. 37. 
concepto de naturaleza mantenido por la corriente principal de la utopía moderna. A su juicio, la naturaleza es una entidad salvaje desprovista de significado y cronológicamente anterior al hombre que la todopoderosa razón debe humanizar y domesticar a fin de aplacar la necesidad y obrar el reinado de la voluntad. Es por eso que el perfeccionamiento del hombre cosechado tras la transformación revolucionaria del nomos solo será integral si se acompaña de la transformación revolucionaria de la physis. Tamaño propósito oscila entre el dominio de la naturaleza-natural ejercido por el hombre primero y la creación de la naturaleza-artificial ejercida por el hombre primario. En el primer supuesto, hegemónico hasta hace bien poco en la literatura utópica, la naturaleza es tildada de chapucera y defectuosa, exponiéndose ipso facto al perfeccionamiento, bien reproduciéndola sin incluir las taras originales, bien optimizándola tecnológicamente. En el segundo, hegemónico a día de hoy, pero barruntado desde los orígenes del género utópico, la naturaleza-natural aparece como un ámbito coartador felizmente rebasado cuya ausencia se suple con productos artificiales milimétricamente ajustados a las necesidades humanas y con la edificación de un entorno de repuesto mejor que el original. En cualquiera de los dos casos salta a la vista que la naturaleza cumple el papel de adversaria a batir. ¿Por qué se percibe así a la naturaleza? Porque el individuo utópico, intensamente humanista y antropocéntrico, receloso de su autonomía y potestad, desconfía de, y demoniza a, lo que él no controla o manufactura. Disciplinando y posteriormente superando a la naturaleza logra abatir al agente que osaba desafiar a su autodeterminación y erigirse, con todo lo que ello supone, en la única instancia autopoiética.

La minusvaloración de la naturaleza y el designio de perfeccionarla se articula utópicamente en torno al apogeo de la técnica que a partir del Renacimiento marginaría la vida contemplativa del erudito rodeado de libros antiguos en favor de la vida activa del ingeniero rodeado de inventos nuevos. Ello no es óbice para que en algunas de las obras primigenias pervivan ecos del paradigma contemplativo, incluso fragmentos naturalistas de sello aristotélico procedentes de las éticas helenísticas. Véase si no la Utopía de Moro, donde se informa (mutatis mutandis puede afirmarse de La Ciudad del Sol de Campanella) ${ }^{3}$ de que los utopianos tienen "por un culto grato a Dios la contemplación de la naturaleza y la alabanza que de ahí brota"4. Fieles a este fervor, conciben el placer como "todo movimiento y estado del cuerpo o del espíritu cuya vivencia en conformidad con la naturaleza deleita"5. Aunque estos credos no dejan lugar a dudas de la presencia naturalista en la obra moreana, existen otros que los cuestionan. Merece destacarse el hecho harto sabido de que la isla de Utopía, antiguamente una península, es un espacio sintético, orquestado por el fundador Utopo para aislar a la sociedad ideal de las sociedades decadentes contiguas ${ }^{6}$. Las loas a la naturaleza-natural florecen así en los dominios de la mayor naturaleza-artificial jamás creada, y son pronunciadas por gentes que presumen de trasplantar los bosques de un lugar a otro para que los troncos se hallen más cerca de las ciudades ${ }^{7}$. La anécdota tiene su miga, pues demuestra a las claras, más allá de los alegatos pro-naturaleza que se quisieran citar, el someti-

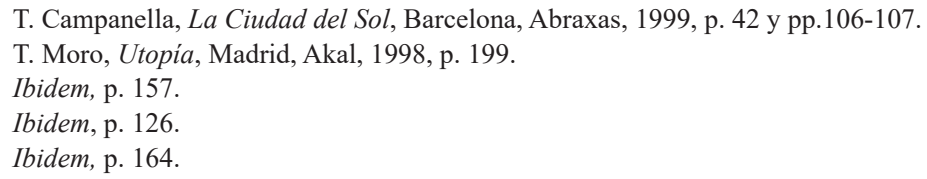


miento de lo natural (recuérdese igualmente el papel subsidiario del campo y de la agricultura en la novela de Moro) ${ }^{8}$ a lo urbano.

Menos ambivalente se adivina la postura de Bacon en la Nueva Atlántida. El representante de la Casa de Salomón exhibe a los visitantes las obras perpetradas por la ingeniería post-aristotélica del lugar:

hacemos artificialmente que los árboles y las flores maduren más temprano o más tarde que como corresponde y que crezcan y se reproduzcan más rápidamente de lo que lo hacen de forma natural. Los hacemos también artificialmente, de mucho mayor tamaño de lo que son por naturaleza... También hacemos que cambien de color, forma, actividad, de muchas maneras 9 .

En Sinapia carecen de logros tan sorprendentes, pero cuentan con conocimientos técnicos que les ayudan a "fertilizar las tierras estériles aunque sean arenales muertos..., y hacer manantiales de agua adonde no los hay". Además, "hacen pastas que imitan las pieles de los animales y, finalmente, no hay cosa en la naturaleza que no imiten, mejorada para los usos humanos"10. El interlocutor de El año 2440 aclara que la finalidad del saber radica en "conocer el movimiento secreto de las cosas y extender la dominación del hombre" ", máxima que inspira, entre otras hazañas, la construcción de "torrentes y cataratas artificiales"12. Cabet imprimió a su utopía decimonónica idéntica directriz: "Dondequiera que se tienda la vista todo está perfeccionado, admirablemente perfeccionado... Por ejemplo: tú has visto en el jardín una especie de melón monstruoso y de un gusto más exquisito que los demás"13.

La mejora de la naturaleza activada por la utopía urbana busca el bienestar y omnipotencia del hombre interviniendo en ella con medios científicos y tecnológicos. Como parte del cometido, destruye las partes fastidiosas del mundo natural. El icariano Monsieur Mirol rescata la maniobra moreana: "La República ha adoptado un sistema enteramente nuevo respecto a los bosques... Dispuso que se cortasen los que estuviesen mal colocados, o de una explotación difícil, o que pudiesen ser reemplazados por productos más ventajosos"14. El narrador de Hombres como dioses rememora cómo siglos atrás "la atención de la comunidad Utópica se desvió hacia la muy acariciada idea de la exterminación sistemática de las especies molestas y dañinas" 15 . Asombrado, el señor Barnstaple se percata de que "la escardadura y cultivo del reino de la naturaleza llevada a cabo por el hombre aparecía ante él como la fase más natural y necesaria a la vez en la historia de la humanidad. Después de todo - decía para sí mismo - fue una gran invención decir que al hombre se le crió jardinero" 16 . La ambición de remendar los fallos de la naturaleza y eliminar aquello natural adjetivado de inconveniente e ineficiente vertebra La isla del Gran Experimento, ignota utopía donde cualquier cosa se fabrica con "sustancias sintéticas que

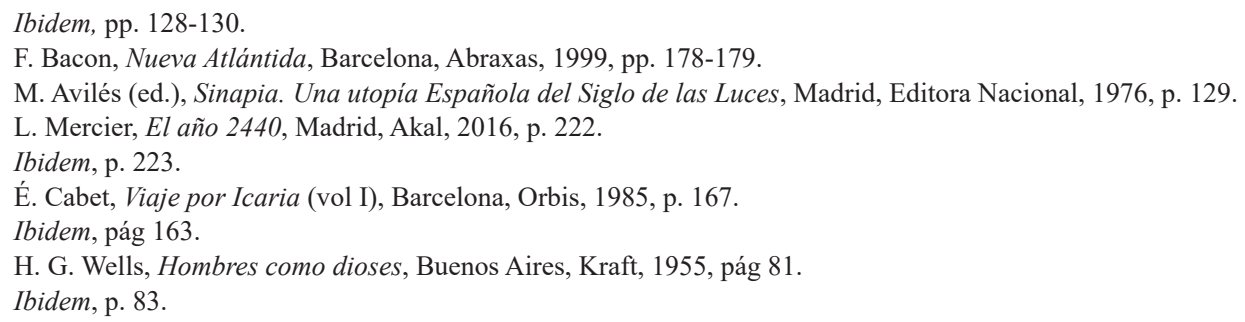


superaban a la naturaleza" 17 y donde gracias a la tecnología se controla el clima "y siempre se disfruta de una constante y benigna temperatura"18. No menos tecnocéntrica, la civilización comunista del porvenir descrita por La nebulosa de Andrómeda ha creado soles artificiales suspendidos sobre las regiones polares que han eliminado "por completo los huracanes y toda clase de turbulentas perturbaciones climatológicas" 19 .Los fragmentos enlazados prueban que la naturaleza no sale muy bien parada de la acción utópica moderna. Cuando finalizan las maquinaciones perfeccionistas de la utopía urbana moderna, de la denigrada naturaleza-natural apenas sobrevive su sombra. No hay, lo estamos apreciando, ni una chispa de conciencia de que la extracción intensa de recursos y la manipulación a gran escala del mundo acarrean efectos secundarios poco pertinentes.

Los defensores de proteger la naturaleza virginal frente a la colonización humana reciben en la utopía urbana el mayor de los desprecios. Uno de los residentes del orden social retratado en Hombres como dioses sostiene que quienes proponen una existencia más apegada a lo natural "no se atreven a averiguar lo que nuestra Madre Naturaleza es... No comprenden que abstraída de nuestros ojos y voluntades ella es irreflexiva y ciega. No es horrenda, es espantosa" ${ }^{20}$. En Una utopía moderna, Wells reproduce el diálogo establecido entre el protagonista y un nostálgico de la naturaleza pura. El disidente ruralista se pregunta: "¿por qué los hombres han de desempeñar siempre el papel de microbios sobre la faz de la tierra?"21. Acto seguido, concluye con una declaración de intenciones hoy bien conocida entre los círculos bioconservacionistas: "lo natural ha desaparecido de la tierra; ahora es preciso descubrirlo de nuevo y, como el polvo de oro, lavarlo de todas las impurezas" ${ }^{\prime 2}$. Los adjetivos lanzados por el héroe de la novela contra este personaje resultan muy ilustrativos de la estigmatización utópica de la naturaleza. "Charlatán"23, "Fantástico proveedor de absurdos" 24 e "imbécil intelectual"25: así es clasificado por el utopista estándar de la modernidad el "apóstol de la Naturaleza"26.

Compartiendo paradigma con Wells, Gabriel Tarde describe en Fragmento de historia futura una sociedad subterránea levantada allende la naturaleza. Este libro maximiza la satanización de la naturaleza-natural y la idealización de la naturaleza-artificial, anticipándose a las dinámicas postmodernas. El orador siente repugnancia de los días en que la humanidad habitaba sobre la superficie del planeta, expuesta a los dictados naturales: "Todas las noches... el sol le ordenaba a la vida social su interrupción, y la vida social se interrumpía. ¡Y la humanidad era hasta ese punto esclava de la naturaleza! Y no lograba, ni siquiera soñaba en librarse de esta esclavitud que pesó tanto y tan inadvertidamente... sobre el curso contenido de su progreso"27. Afortunadamente, asegura, los utópicos anidan en la "naturaleza elegida y perfecta

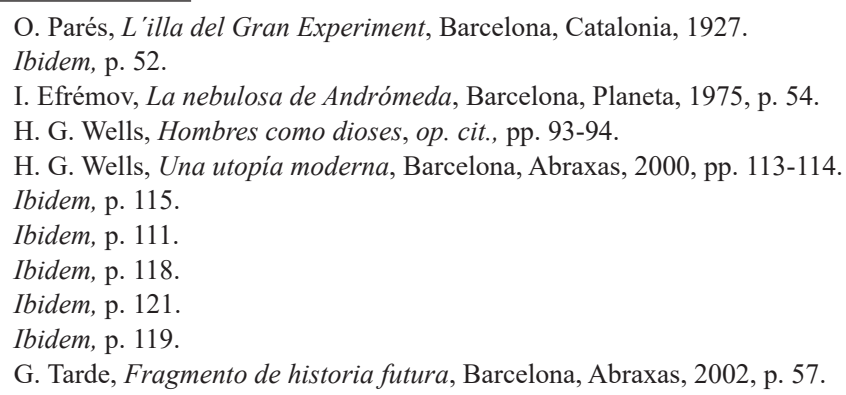


que se ha humanizado" 28 . Tarde vuelve a vilipendiar a la naturaleza en otro pasaje imponente:

un erudito... encontró gran cantidad de planchas fonográficas y cinematográficas, y esas planchas nos han permitido oír de pronto todos los antiguos ruidos de la naturaleza... El canto del ruiseñor, sobre todo, provocó un verdadero despecho... En efecto, el más malo de nuestros conciertos es más musical que esta supuesta sinfonía natural a gran orquesta ${ }^{29}$.

Pero el meollo antinaturalista estelar del relato llega cuando el protagonista se refiere a los antiguos habitantes del campo: “¡Rurales! Este es un extraño arcaísmo. Pescadores, cazadores, labradores, pastores: ¿se comprende hoy día el significado de estas palabras? ¿Por un instante ha meditado alguien en la vida de este ser fósil del que tanto se suele hablar en los libros de historia antigua al que llamaban campesino?"30.

A estas alturas de la discusión queda fuera de toda duda que la efigie de Prometeo desencadenado sobrevuela los confines de la utopía urbana de la modernidad, transfiriendo al ámbito de la literatura popular la exhortación cartesiana a "hacernos dueños y poseedores de la naturaleza" ${ }^{31}$ y la certeza baconiana de que "la ciencia y el poder humano vienen a ser lo mismo" "32. No menos involucrada en el prometeísmo utópico moderno se encuentra según Isaiah Berlin la filosofía kantiana, piedra de toque de la filosofía de la libertad del idealismo posterior que confirió preeminencia a la voluntad ante el ciego mecanicismo y determinismo de la naturaleza sensible. Para conseguirlo, Kant tuvo que postular la existencia de una naturaleza nouménica paralela donde los seres humanos soslayan la causalidad fenoménica y — digámoslo con Hegel - neutralizan a esa "aburrida historia sujeta al mismo ciclo"33 que es la vida natural. Arropado por tal planteamiento, Kant sugirió que "cuando desarrolla su máximo potencial humano y alcanza su más alta nobleza, entonces el hombre domina la naturaleza, es decir la moldea, la rompe, le impone su personalidad, hace lo que él elige hacer" ${ }^{34}$.

\section{Proteger a la naturaleza I: La utopía del campo}

Las utopías del campo también se fundamentan sobre el dilema natural-artificial, pero lo resuelven a la inversa. De sierva estigmatizada, la naturaleza deviene en Madre a reverenciar que contrarresta simbólica y físicamente la masificación y automatización de la ciudad. Lo natural se desliga de la representación positivista y de los adjetivos peyorativos y se antoja ahora emancipador y orgánico, instituyéndose en

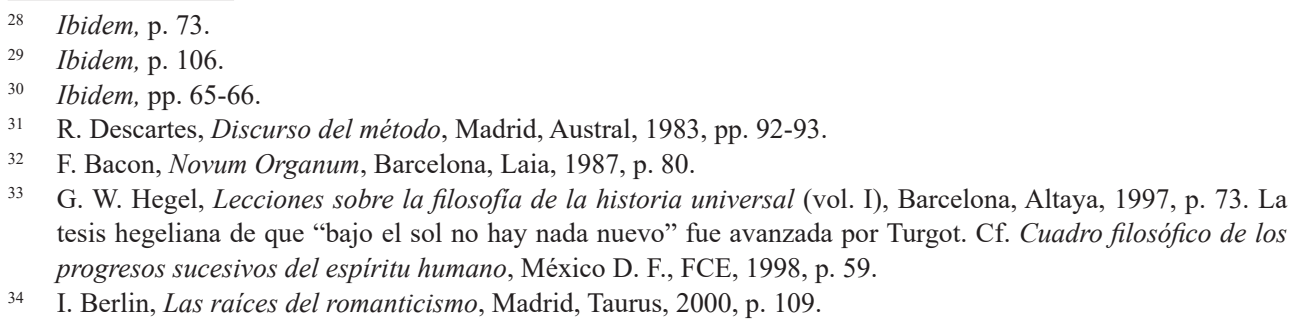

34 I. Berlin, Las raices del romanticismo, Madrid, Taurus, 2000, p. 109. 
la cuna de la genuina liberación humana. Thoureau, uno de los pensadores envueltos en la producción de este imaginario, pontificó: "He aquí nuestra inmensa, salvaje, aulladora madre, la Naturaleza, presente por doquier con tanta belleza y tanto afecto hacia sus hijos... y sin embargo, qué pronto hemos abandonado su pecho para entregarnos a... una civilización destinada a un pronto fin" ${ }^{35}$. De instrumentos de la emancipación, la ciencia y la tecnología devienen por su parte en herramientas potencialmente nocivas cuyo curso invasivo es preciso interrumpir. Dependiendo de la obra, la utopía del campo abogará ora por restringirlas, ora por abandonarlas. Catalizando ambas iniciativas, resuena la famosa tesis rousseauniana de que "la naturaleza ha querido preservarnos de la ciencia, como una madre arranca un arma peligrosa de las manos de su hijo" ${ }^{36}$. Es así que la intensidad insuflada por la utopía del campo a los llamamientos en pro de la comunión armoniosa con la naturaleza es directamente proporcional a la intensidad con la que desconfía de lo científico-tecnológico por inspirar una concepción del progreso que sabotea la comunión citada.

William Morris ofrendó con Noticias de ninguna parte (escrita tras la desazón que le ocasionó la baconiana Mirando hacia atrás de Bellamy) la más influyente de las utopías anti-urbanas. Personificando la alabanza de las comunidades medievales habitual en esta tendencia utopista ${ }^{37}$, uno de los personajes expone que la perfección circundante florece "del espíritu de la Edad Media, porque entonces el cielo y una vida futura eran verdades tan evidentes para aquellos hombres que constituían parte de su vida en la tierra. Una tierra que amaban y embellecían por este mismo hecho"38. Elena, protagonista femenina, vehicula un sentimentalismo ante la naturaleza totalmente incompatible con el vislumbre wellesiano: “ ¡La tierra, su vegetación, su vida! ¡Oh, si pudiese decir, si pudiese mostrar cuánto la amo!’39. Pese al naturalismo cuasi pastoral circundante, el Londres futurista de Morris no prescinde completamente de la tecnología mecánica. Sus ciudadanos aceptan que el bienestar pasa por emplear máquinas y dominar la naturaleza, pero solo cuando sea estrictamente necesario, evitando los abusos industrialistas del orden económico-social preliminar ${ }^{40}$.

Publicada en 1975, Ecotopía lideró el giro ecologista de la utopía efectuado al son de la ya visible degradación medioambiental, el empuje de la conciencia verde y los movimientos contraculturales. El cronista del relato, William Weston, informa de un modus vivendi semejante al de Noticias de ninguna parte, devoto de lo campestre y medieval, aunque tecnófobo y eco-céntrico en mayor grado:

lo que más me llama la atención es la aspiración de sus gentes de vivir en equilibrio con la naturaleza, de caminar con ligereza sobre la tierra, de tratarla como a una madre. No sorprende, pues, que para una moral semejante la mayoría de progresos, modos de trabajo y productos industriales resulten sospechosos: ¿quién haría pasar un bulldozer sobre el cuerpo de su propia madre? ${ }^{41}$.

35 D. Thoreau, Caminar, Madrid, Árdora, 2001, p. 47.

36 J. J. Rousseau, Discurso sobre el origen y los fundamentos de la desigualdad entre los hombres y otros escritos, Madrid, Tecnos, 2002, p. 19.

37 A. L. Morton, Las utopías socialistas, Barcelona, Martínez Roca, 1970, p. 158.

38 W. Morris, Noticias de ninguna parte, Barcelona, Minotauro, 2004, p. 150.

39 Ibidem, p. 224.

40 Ibidem, p. 75.

41 E. Callenbach, Ecotopía, Zaragoza, Trazo Editorial, 1980, p. 48. 
Weston transcribe los dos dogmas ecotopianos. Primero, que el hombre "debe encontrar la felicidad no en el hecho de dominar a las demás criaturas terrestres, sino en vivir en armonía con ellas" ${ }^{42}$. Y segundo, que el hombre debe conseguir, con la máxima del reciclaje, el no-consumo y el impacto medioambiental cero "devolver a la naturaleza a su situación natural" "3. Las autoridades de Walden Tres, novela del mismo período, coinciden en buscar "la restitución del equilibrio perdido..., plantar nuevos bosques, limpiar los ríos, volver a sembrar peces en los lagos" ${ }^{44}$, resucitar, en suma, a la naturaleza inmaculada, previa a las injerencias de la civilización moderna. No es preciso remarcar que tamaño designio prueba que las utopías del campo sostienen una noción esencialista de naturaleza. Suponen, las utopías urbanas de la modernidad también lo hacen, que en el pretérito, antes del desembarco de la humanidad, hubo una naturaleza impoluta, estable y armoniosa. Y quieren, a la inversa que los acólitos wellesianos, recobrarla bajo el supuesto de que la purificación moral del hombre será inviable sin la purificación ecológica del mundo físico.

El mismo año de publicación de Ecotopía Joanna Russ dio a conocer El hombre hembra, puntal de la utopía ecofeminista. Whileaway, el idiosincrásico orden social esbozado por Russ, se funda en el precepto de la infrapoblación y carece de "verdaderas ciudades... Es tan bucólico que a veces una se pregunta si la última sofisticación no nos llevará a una especie de edad prepaleolítica, un jardín sin ningún artefacto" ${ }^{45}$. Las whileawayanas, dotadas de un don especial para la ciencia avanzada, poseen tecnologías hoy impensables, pero difieren de la mentalidad baconiana consustancial a los varones extintos al poner en práctica "el tipo de mente que convierte las áreas industriales en jardines, que mantiene zonas de la naturaleza salvaje donde nadie vive durante mucho tiempo, que salpica por todo el planeta paisajes, montañas" ${ }^{\prime 46}$.

Casi un siglo antes de que Callenbach y Russ incorporaran las preocupaciones medioambientales al repertorio temático de la utopía, el precursor del ecologismo Henry Hudson imaginó en La era de Cristal un futuro distante donde las ciudades han desaparecido y la naturaleza ha recuperado la exuberancia primigenia fantaseada por los ideólogos de Ecotopía y Walden Tres. Los apenas dos millones de seres humanos que pueblan el planeta se agrupan en dispersas comunidades agrícolas de carácter místico-matriarcal que tienen por deidad a la Naturaleza y por método medioambientalista el escrupuloso control demográfico. Juntos condenan el temple prometeico que enloqueció a los antecesores de orgullo, corrupción y vanidad, llevándoles a la autodestrucción. El juicio condenatorio refleja a las claras un imaginario culpabilizador que compara el dominio de la naturaleza con un pecado merecedor de castigo: "acuciados por el deseo de descubrir los secretos de la naturaleza, no vacilaron en mancharse las manos de sangre... Porque en su locura esperaban que el conocimiento les diera el dominio absoluto sobre la naturaleza, arrebatando al Padre la prerrogativa sobre el mundo" 47 .

\footnotetext{
Ibidem, p. 67.

Ibidem, p. 86.

R. Ardila, Walden Tres, Barcelona, CEAC, 1979, p. 170.

J. Russ, El hombre hembra, Barcelona, Bruguera, 1978.

Ibidem, p. 80.

47 W. H. Hudson, La era de cristal, Barcelona, Minotauro, 2004, p. 66.
} 


\section{Proteger a la naturaleza II: La distopía}

La distopía literaria estándar comparte tabla de valores con las utopías ruralistas en los aspectos referentes a la dilemática natural-artificial, pero agrega matices vinculados a la teoría de la racionalidad sumamente interesantes. Opina el distópico que el lema de perfeccionar técnicamente a la naturaleza es un eufemismo diseñado para ocultar el sadismo y soberbia de una voluntad de poder insaciable: "Es necesario - Ronald Laing sintetiza el ethos al que nos referimos-, sentirse muy libre para manipular la Madre Naturaleza, la Diosa Tierra misma, la verdadera obra personal del mismo Dios, en forma tan despiadada" ${ }^{48}$. Dado el rumbo suicida del progreso que percibe, la distopía estándar de la modernidad recomienda a los disconformes evadirse de la metrópoli alienada, regresar a la Madre Naturaleza con total humildad y aceptar el estatuto de creatura, so riesgo de padecer males sin igual (deshumanización, alienación, totalitarismo...). Divulgando estimaciones típicas de Ruskin, Carlyle y demás abanderados de la kultur ${ }^{49}$, la distopía aboga por un sujeto extraño a la soberanía cartesiana del hombre primero y a la ambición demiúrgica del hombre primario; un sujeto, pues, a expensas de un poder no-humano que, a cambio de abrigarlo y restituir su individualidad, le impone férreos condicionantes a su hacer. Ahora bien, mientras la utopía del campo presenta abiertamente una utopía colectivista alternativa a la estándar, la distopía se centra en la estigmatización de la utopía urbana, insinuando a partir de la negación del sistema descrito una alternativa rural de talle liberal. Así las cosas, el utópico del campo vuelve a la naturaleza junto a toda la humanidad tras la exitosa revolución contra el orden industrializado; el distópico tras fugarse, dejándola tal cual estaba, de la urbe desnaturalizada y desnaturalizadora, divorciada del medio natural por cúpulas y murallas, coyuntura típica de clásicos como $\operatorname{Nosotros}^{50}$, Cuando el durmiente despierte ${ }^{51}$, Un mundo feliz ${ }^{52}$ y Farenheit $451^{53}$.

En tanto que descripción de Estados totalitarios tecno-cientificistas del mañana, la distopía rectifica a la utopía urbana y a la propia modernidad alegando que el dominio de la naturaleza externa antecede necesariamente al dominio impecable de los hombres (de la naturaleza interna). Las novelas distópicas emiten de esta manera una versión para todos los públicos de la premisa según la cual la interrelación de un avasallamiento y otro tiene en la transformación baconiana del conocimiento en poder y en la transformación mecanicista de la naturaleza en materia huérfana de fines y valores a dos de sus resortes. La a menudo distópica primera generación de la teoría crítica encaró análoga premisa desde el dualismo sujeto-objeto, enfatizando, en efecto, que fue la conversión cientificista de la naturaleza en "mera materia primera" ${ }^{44}$ (en objeto) lo que permitió divorciarla del ser humano (mutado en sujeto), justificar el mando de este sobre ella y apagar cualquier conato de culpabilidad. Al desprenderse de una lógica consagrada a la dominación, el divorcio mencionado mimetizó la misma "distancia frente a la cosa que el señor logra con el siervo" 55 .

\footnotetext{
R. D. Laing, ¿QQué ocurre con la mente?”, en S. Kumar (ed.), Para Schumacher, Madrid, Blume, 1981, p. 31.

P. Capanna, La tecnarquía, Barcelona, Barral, 1973, p. 213.

Y. Zamyatin, Nosotros, Madrid, Alianza, 1993, p. 112.

H. G. Wells, Cuando el durmiente despierte, en Obras completas I, Barcelona, Plaza \& Janés, 1962, p. 797.

A. Huxley, Un mundo feliz, Barcelona, Plaza \& Janés, 2001, p. 115.

R. Bradbury, Farenheit 451, Barcelona, Plaza \& Janés, 1965, p. 160.

M. Horkheimer, Crítica de la razón instrumental, Trotta, Madrid, 2002, p. 119.

T. Adorno \& M. Horkheimer, Dialéctica de la Ilustración, Madrid, Trotta, 1997, p. 68.
} 
Programada para liberar a la humanidad, la Ilustración se despliega para esta exégesis a hombros de una racionalidad autoritaria - la racionalidad instrumental, ergo tecnocrática, formal, subjetiva - que durante su búsqueda irreflexiva de resultados inmediatos termina cebándose en el ser humano y transformándolo también a él en objeto que racionalizar y manipular conforme a las mismas directrices funcionalistas empleadas con la naturaleza externa. No otro es a ojos de los frankfurtianos el origen del totalitarismo explícito o implícito. Depredadora y hambrienta de poder, vienen a exponer, la irracional racionalidad instrumental lleva al límite la lógica autorrefutatoria que la mueve y naturaliza con vistas a someterlo a quien debiera emancipar. Horkheimer escribe: "si al ser humano se le asegura que es naturaleza y sólo naturaleza, entonces lo único que queda ya es compadecerlo. Pasivo como todo lo que es sólo naturaleza, ha de ser un objeto de «tratamiento», un ser, en definitiva, dependiente de una conducción más o menos benevolente" ${ }^{\text {"56 }}$. Marcuse perseveró en la idea: "la ciencia, gracias a su propio método..., ha proyectado y promovido un universo en el que la dominación de la naturaleza ha permanecido ligada a la dominación del hombre: un lazo que tiende a ser fatal para el universo como totalidad"57. La Dialéctica de la Ilustración compendió el episodio sin florituras: "lo que los hombres quieren aprender de la naturaleza es servirse de ella para dominarla por completo, a ella y a los hombres" 58 .

Heidegger llegó a conclusiones equivalentes manejando principios distintos. A su parecer, la esencia de la técnica no se encuentra condicionada por la subjetividad, la ciencia, el sistema económico o los estados. Al contrario, es la causa de todo ello: "el hecho de que el hombre se convierta en sujeto y el mundo en objeto, es una consecuencia de la esencia de la técnica que se establece a sí misma y no al contrario" 59 . Aupado a la categoría de sujeto, el hombre moderno "se alza como el productor que se autoimpone y eleva ese alzarse al nivel de un dominio incondicionado"60 bajo cuya autoridad la "tierra y la atmósfera se convierten en materias primas" y el hombre mismo "en material humano" ${ }^{1}$. Curiosamente, la humanidad muta en "material" justo en el lapso de su entronización suprema, cuando la conciencia antropocéntrica del humanismo florecido de la metafísica cartesiana "explica y valora lo ente en su totalidad a partir del hombre y para el hombre" ${ }^{62}$. Es por eso que urge según Heidegger rebajar al hombre a la categoría de pastor del Ser, condición modesta si se la compara con la protagórica "medida de todas las cosas", pero idónea para desactivar la tiránica subjetividad metafísica y recobrar la tierra herida por el nihilismo tecnológicamente consumado.

Con todo, el hado de la naturaleza puede ser peor que el de servir de botín del hombre. Hemos reseñado de pasada cómo en la mayoría de distopías modernas la naturaleza externa sobrevivía cual alteridad tras las cúpulas que la escindían de la ciudad. Pues bien, a inicios de los setenta, cuantiosas obras del género acompañaron a las utopías campestres del momento y dieron su particular giro ecologista novelando los pavores ecológicos agitados, a propósito de la superpoblación, el

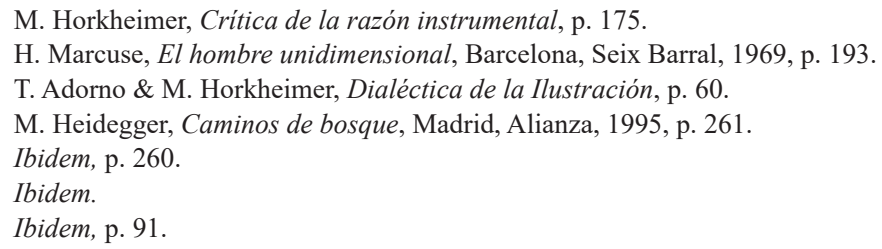


DDT y la energía nuclear, por Paul Ehrlich, Barry Commoner, Rachel Carson y demás apóstoles de la calamidad ${ }^{63}$. A diferencia de las utopías del campo, las distopías medioambientalistas no escenificaron futuros donde la naturaleza virgen ha reconquistado el terreno perdido, sino futuros donde la naturaleza ha fallecido por obra y gracia de la polución global o cualesquiera otros desastres propiciados directa o indirectamente por la ciencia y la tecnología. El objetivo ya no consistía en reivindicar a la naturaleza revelando el carácter totalitario de la desnaturalización, sino en denunciar el carácter ecológicamente insostenible del progreso prometeico. Si la distopía moderna estándar loaba a lo natural por amparar la libertad individual, la postmoderna lo hará por un motivo mucho más elemental; por amparar la vida humana. El peligro de la ausencia de naturaleza ya no reside en la alienación y estandarización del ser humano, sino en su extinción. En los textos distópicos pertenecientes a la ola ecológica —El rebaño ciego de John Brunner y iHagan sitio! ¡Hagan sitio! de Harry Harrison son, junto a la película Naves misteriosas (Douglas Trumbull, 1972), muestras representativas - la naturaleza no aparece siendo dominada. De hecho, la naturaleza-natural no aparece en absoluto, pues fue asesinada por la civilización otrora dominadora, condenada desde entonces al pronto ocaso. A lo sumo, perviven grabaciones o restos de lo natural guardados bajo llave. Max Ehrlich recreó esta contingencia en Edicto siglo XXI, novela donde las últimas muestras de naturaleza auténtica (unas cuantas flores, dos rastrojos de hierba, un perro enfermo) se exhiben en un parque estatal fortificado al que asisten las masas para emocionarse ante los despojos crepusculares de la naturaleza y quitarse durante unos minutos la mascarilla de oxígeno ${ }^{64}$. Moderan va más allá y denuncia que a la liquidación de la naturaleza-natural le sucederá la creación de una naturaleza-artificial repugnante e inhumana. El narrador interpela al lector:

Nuestra tierra está tan envenenada por el progreso científico tanto como la suya. Por eso la estamos cubriendo por completo con el plástico estéril, una gran, enorme envoltura de plástico grisáceo, recio, estéril sobre toda la superficie de la tierra... La superficie de nuestro globo será un cuero liso, recio, blanco grisáceo... Los árboles, si los queremos, brotarán en los agujeros del descampado al apretar un interruptor. Las flores florecerán directa y puntualmente en un maravilloso metal floral. Los animales... No habrá animales, a menos que deseemos unos cuantos tigres, leones y cosas así, todos mecánicos, por supuesto, para alguna cacería programada en el bosque mecánico ${ }^{65}$.

Rodeado por el mismo contexto que llevó a la distopía a emprender el giro ecologista, Hans Jonas elevó a la categoría de obligación máxima la labor de asegurar la presencia futura de la humanidad en el planeta. A tal fin, reclamó abandonar el principio utópico de esperanza que a su juicio agrede a la naturaleza y asumir un principio ético de responsabilidad que la resguarde. De acuerdo al punto de vista jonasiano, la raíz del ecocidio yace en la "inevitable dimensión utópica de la tecnología moderna" ${ }^{66}$, siendo así que para avalar la supervivencia postrera del ser humano

Cf. J. Maddox, El síndrome del fin del mundo, Barcelona, Barral, 1974.

M. Ehrlich, Edicto siglo XXI, Barcelona, Grijalbo, 1976, p. 72-75.

D. Bunch, Moderan, Barcelona, Edhasa, 1982, p. 36-37.

H. Jonas, El principio de responsabilidad, Barcelona, Círculo de Lectores, 1994, p. 55. 
sea condición sine qua non disolver el ligamen utopía-tecnología orquestado por el comunismo marxista y limitar el inmenso poder humano conseguido gracias a la técnica mediante una "heurística del temor". La clave de la salvación humana pasa, en resumidas cuentas, por priorizar

la ética de la responsabilidad, que hoy, tras varios siglos de euforia posbaconiana, prometeica (en la que también el marxismo tiene su origen), ha de poner freno al desbocado impulso hacia delante. Dado que de otro modo sería la propia naturaleza la que lo hiciera poco más tarde y de una manera terriblemente más dura, esto no sería más que un dictado de la prudencia juiciosa unido a una simple consideración para con nuestros descendientes ${ }^{67}$.

El inconveniente substancial del programa de Jonas radica en que prospera sobre una simplificación abusiva del complejísimo fenómeno utópico. En el nivel filosófico lo reduce a la aportación, sin duda vital, de Bloch, pasando por alto infinidad de teorizaciones no menos significativas. En el nivel práctico establece, para matar a dos pájaros de un tiro, la muy conservadora concurrencia entre utopía y totalitarismo. Y lo hace a la manera previsible: sobredimensionando los contactos entre ambos elementos y camuflando sus enormes discrepancias ${ }^{68}$. En el nivel metodológico omite por mor del argumento que el utopismo cuenta con obras (arriba hemos citado varias) pregoneras de la humildad y responsabilidad ante la naturaleza. Asimismo, la asunción de supuestos heideggerianos cuestionables - el principal de ellos asegura que la tecnología escapa al control humano y determina por sí sola el destino de la civilización - le lleva a postular una relación causal inevitable entre el dominio de la naturaleza-natural y la destrucción del medioambiente necesitada, nos parece, de un mejor argumentario.

\section{Crear a la naturaleza I}

Durante la modernidad la naturaleza independiente del hombre se inclinó ante el dominio del ser humano. Durante la postmodernidad, la naturaleza pierde su independencia y se descubre como una creación del hombre. Factores como la globalización capitalista y la transformación de islas, bosques y glaciares en destinos turísticos junto a la consolidación de la ingeniería genética, la constatación del efecto invernadero y la multiplicación de las metrópolis arrasan - para despecho de distópicos y utópicos del campo - lo natural y estrenan el monopolio planetario de lo artificial. Tratamos con un indicio trascendental del espíritu de nuestra época, presto a invalidar el entramado binario de la cosmología moderna. En el caso que nos ocupa, el dilema natural-artificial (y los dilemas asociados: orgánico-mecánico, campo-ciudad, hecho-valor, ciencias de la naturaleza-ciencias del espíritu) deja de ser funcional para muchos pensadores porque nada natural — nada auténticamente salvaje, primigenio - subsiste. Solo topamos con artificios, con esferas y criaturas tecnificadas, simbolizadas y mercantilizadas, siendo así que la única naturaleza ontológicamente plausible es la naturaleza-artificial. Perry Anderson ofrece una paráfrasis económica del pormenor:

Ibidem, p. 354.

68 M. Abensour, "Utopía y emancipación”, Revista Minerva, n 15, 2010, p. 48. 
En un universo del que se ha erradicado... todo rastro de naturaleza, la cultura se ha expandido necesariamente hasta hacerse virtualmente coextensiva a la economía misma, no sólo como base sintomática de algunas de las mayores industrias del mundo... sino mucho más profundamente, en tanto que todo objeto material y todo servicio inmaterial se convierte a la vez en signo complaciente y mercancía vendible. En este sentido, la cultura, en cuanto tejido ineludible de la vida bajo el capitalismo, es ahora nuestra segunda naturaleza ${ }^{69}$.

El registro de la desnaturalización conoce precursores excelsos. Spengler, por ejemplo, avisó con la mente puesta en la técnica fáustica de que "la imagen de la tierra, con sus plantas, animales y hombres se ha modificado... Un mundo artificial atraviesa y envenena el mundo natural" ". Ortega y Gasset sostuvo que "el hombre no vive ya en la naturaleza sino que está alojado en la sobrenaturaleza que ha creado"71. En la aurora del contexto postmoderno, Jonas levantó acta del pormenor vinculando el advenimiento de la naturaleza-artificial con la destrucción de la naturaleza-natural: "La diferencia entre lo artificial y lo natural ha desaparecido, lo natural ha sido devorado por la esfera de lo artificial, y, al mismo tiempo, el artefacto total - las obras del hombre convertidas en mundo, que actúan sobre él y a través de él- está engendrando una nueva clase de naturaleza"72. Esta clarividente exégesis se basa en tres hipótesis que tendrán un largo recorrido en ciertos segmentos de la cultura postmoderna. Por una parte, la demolición de la disyunción naturaleza-cultura. Por otra, el hecho de que viene ocasionada por la expansión absoluta del orden artificial, que termina absorbiendo al orden natural y permutando el dualismo previo por un monismo extremo. En último lugar, la creación humana de una naturaleza sintética, plenamente planificada, simbolizada. Lo llamativo es que Jonas no se atiene a los dictámenes por él mismo formulados, pues si "lo natural ha desaparecido", ¿qué sentido tiene apelar a su cuidado?

Justo una década después de la aparición de El principio de responsabilidad, Bill McKibben publicó El fin de la naturaleza, ensayo de divulgación tan anti-baconiano y anti-antropocéntrico como la indagación de Jonas. En esencia, lo que McKibben argumentó es que el apocalipsis ecológico anticipado por las distopías ecologistas de los setenta se ha realizado de cierta manera. Atendiendo a las consecuencias metafísicas del deterioro de la capa de ozono, de la presencia de pesticidas humanos en el tejido de la vida y del cambio climático, El fin de la naturaleza informó que hemos convertido "hasta el último rincón de la Tierra en algo artificial, en una obra del hombre. Hemos privado a la naturaleza de su independencia, y eso resulta fatal para su sentido. La independencia de la naturaleza es su sentido: sin eso, no queda nada

69 P. Anderson, Los orígenes de la posmodernidad, Barcelona, Anagrama, 2000, p. 78. Ni que decir tiene, es preciso indicar, que la muerte de la naturaleza estimula la irrupción de un sinfín de revivals de naturaleza. Las cumbres del clima a las que nos referíamos al inicio de este trabajo, junto a síntomas en principio menos trascendentes como el auge de la homeopatía, la crianza natural, la comida ecológica, los derechos de los animales, el determinismo genético y la teoría Gaia muestran que la desnaturalización en curso promueve una demanda masiva (y ambigua) de naturaleza. Véase al respecto: F. Jameson, Las semillas del tiempo, op. cit., pp. 51-52: F. Martorell, "La naturaleza se ha ido para siempre. Esbozo de una ontología del presente a propósito de Fredric Jameson”, Actes XVIII Congrés Valencià de Filosofía, Universidad de València, 2011, pp. 423-437.

70 O. Spengler, El hombre y la técnica, Buenos Aires, Austral, 1947, pp. 67-68.

71 O. Gasset, Meditaciones sobre la técnica, Madrid, Alianza, 1996, p. 14.

72 H. Jonas, El principio de responsabilidad, op. cit., pp. 37-38. 
excepto nosotros"73. La artificialización de la Tierra ocasiona que "cada metro cúbico de aire, cada palmo cuadrado de suelo están indeleblemente señalados con nuestra cruel marca, con nuestra X" ${ }^{\prime 74}$. Apenado porque, digámoslo con James, la huella de la serpiente humana está en todas partes, el autor confía en que, si "limitásemos nuestro número, nuestros deseos y nuestras ambiciones, tal vez la naturaleza pudiera volver algún día a su labor independiente"

El testimonio de Jonas y McKibben - la llegada de un orbe completamente desnaturalizado - se inscribe en la sección agorera de un ambiente intelectual adverso al antropocentrismo muy envalentonado y polifacético. En virtud de un abordaje del asunto restringido con frecuencia a lo textual y etnográfico, cuantiosos investigadores recientes vinculan el advenimiento de la naturaleza-artificial a la deconstrucción de la idea falogocéntrica de naturaleza-natural y al reconocimiento, atribuido por los realistas a un atracón de giro lingüístico, de que tal cosa (la naturaleza dada, en sí misma, separada de las tramas discursivas) jamás existió. Fue siempre un constructo $^{76}$. Al revés que Jonas y McKibben, los teóricos aquí asentados tratan el fin de la naturaleza cual evento liberador, en la medida en que interrumpe, aseguran, la retahíla de lastres metafísicos e inspira modalidades no despóticas de entender y relacionarnos con el mundo. Algunos de ellos (Latour y sus compinches, sobre todo) rechazan que el fin de la naturaleza obedezca a la absorción cuasi fichteana del objeto por parte del sujeto. Obedece, a su posthumanista manera de comprender las cosas, al desmantelamiento de las fronteras edificadas a priori entre ambos y a la multiplicación por doquier de híbridos y cyborgs que funden lo natural con lo cultural y viceversa, dejando a la sustancialidad inconfundible del sujeto en nada ${ }^{77}$.

Sea como fuere, al complementar la óptica de Jonas y McKibben con la óptica deconstruccionista queda patente que:

la muerte de la naturaleza es material y conceptual al mismo tiempo. Las condiciones materiales han cambiado. Los humanos han penetrado en cada recodo de la

\footnotetext{
B. McKibben, El fin de la naturaleza, Barcelona, Ediciones B, 1990, p. 81.

Ibidem, p. 120.

Ibidem, p. 248.
}

76 David Demeritt firma una taxonomía de las corrientes unidas a esta certeza. Cita al construccionismo filosófico de Hacking, a la crítica de la ideología de Smith, a la fenomenología de Hannigan, a la sociología del conocimiento científico de Woolgar, a la teoría del discurso de Butler y a la sociología simétrica de Latour. Véase: D. Demeritt, "What is the social construction of nature? A typology and sympathetic critique", Progress in Human Geography, 26, 2002, p. 770. Arturo Escobar enfoca la cuestión en términos constructivistas y enumera cuatro grandes grupos: el constructivismo dialéctico de Lewontin, el interaccionismo constructivista de Oyama, el construccionismo fenomenológico de Ingold y el postestructuralismo constructivista de Haraway. A. Escobar, "Epistemología de la naturaleza y colonialidad de la naturaleza. Variedades de realismo y de constructivismo", en A. Viola (ed.), Antropología del desarrollo. Teorías y estudios etnográficos en América Latina, Barcelona, Paidós, pp. 55-59.

77 Cf. B. Latour, Nunca hemos sido modernos, Madrid, Debate, 1993, pp. 13, 80-81; M. Simmons, "The End and Rebirth of Nature? From Politics of Nature to Synthetic Biology”, en Philosophica, 47, 2016, pág 111; G. Patella: "Naturaleza, ciencia y democracia. Bruno Latour y las políticas de la naturaleza", Argumentos de razón técnica, 8, 2005, pp. 161-168. La antropología social postmoderna certifica la condición no universal del binomio naturaleza-cultura explorando cosmologías no occidentales donde lo natural y lo cultural se hibridan. Cf. P. Descola, "Más allá de la naturaleza y de la cultura", en L. Montenegro (ed.), Cultura y naturaleza, Bogotá, Jardín Botánico de Bogotá, 2011, pp. 79, 84-85; A. Escobar, "El lugar de la naturaleza y la naturaleza del lugar: ¿globalización o postdesarrollo?”, en A. Viola (ed.), Antropología del desarrollo. Teorías y estudios etnográficos en América Latina, op. cit., pp. 118-119. 
tierra y sus actividades han alterado la temperatura global, los patrones climáticos y la propia composición de la atmósfera. Los avances en ciencia y tecnología han socavado las fronteras entre el ser humano y el animal, el organismo y la máquina, lo físico y lo no físico... Conceptualmente, es difícil concebir la naturaleza como un inmenso poder primordial que sostiene y amenaza a la cultura, o simplemente como aquello que no es cultura cuando la frontera entre naturaleza y cultura se encuentra tan profundamente vulnerada y se hace patente la asimilación de la naturaleza por parte de la cultura ${ }^{78}$.

\section{Crear a la naturaleza II}

Una mirada superficial a la literatura utópica editada en las últimas décadas basta para confirmar que este género popular bebe del mismo Zeitgeist que los sofisticados deconstructores ${ }^{79}$. De ahí que las utopías postmodernas estándar asuman plenamente la faceta creacionista del hombre primario y den por hecho, a veces por bueno, el fin material y conceptual de la naturaleza-natural. La asunción del constructivismo les lleva a comprometerse con la imagen de una naturaleza-artificial que en virtud de su procedencia humana ya no se concibe como ajena a los hombres, ni por tanto como una otredad hostil a subyugar. Por lo general, entre las utopías modernas y postmodernas pertenecientes al ala urbana del género se mantiene, empero, el temperamento prometeico-humanista de origen, gesto que las enfrenta a la oleada de antihumanismos y posthumanismos que colman el espectro académico.

El temperamento prometeico-humanista mencionado impregna Terraformar la Tierra, novela de ciencia ficción dotada de sólidos impulsos utópicos. Hace millones de años un asteroide acabó con la vida terrestre. En una base lunar habitan los póstumos vestigios de la humanidad, clones producidos periódicamente por androides a partir del ADN procedente de personas del pasado. Multitud de generaciones de clones se relevan con la misión de reactivar la evolución a golpe de biotecnología y nanotecnología. Un androide lo hace constar: "para eso nacisteis. Para ayudar a la naturaleza a curar el planeta... Nacisteis para volver a construirlo todo. La sociedad. La cultura. La civilización. El biocosmos entero. Una responsabilidad terrible" 80. Nótese que el programa terraformador tiene por meta crear a la naturaleza. Crearla materialmente, no simbólica o discursivamente. Mas la naturaleza producida por los clones después de millones de años de trabajo ya no será natural, sino un artificio hecho por otros artificios: "Plantar nueva vida es el primer paso y es vital para reavivar la evolución y dejar que la naturaleza haga su trabajo. O el nuestro" ${ }^{\text {. }}$.

En Jinetes de la Antorcha la humanidad se vio forzada hace siglos a evacuar su planeta natal y surca el espacio a bordo de dos mil cuarenta "naves antorcha",

78 K. M. DeLuca, "The possibilities of Nature in a Postmodern Age: The Rhetorical Tactics of Environmental Justice Groups", Communication Theory, no 2, 1999, pp. 192.

79 Sirva de muestra este extracto de la utopía transhumanista Ciudad permutación: “¿Qué harías tú? ¿Ser humilde en presencia de la naturaleza, y esperar ser recompensado por ello? ¿Crees que Madre Gaia va a perdonarnos, y hacer que todo esté bien, tan pronto como arrojemos nuestros malvados ordenadores? Es demasiado tarde... Ahora todo el ecosistema planetario es un artefacto... y ahora que hemos creado un mundo artificial, queriendo o no, será mejor que aprendamos a controlarlo". G. Egan, Ciudad permutación, Barcelona, Ediciones B, 1998, p. 69.

80 J. Williamson, Terraformar la Tierra, Madrid, Factoría de Ideas, 2007, p. 41.

$81 \quad$ Ibidem, p. 47. 
vehículos descomunales con capacidad para albergar a millones de personas. En el interior de cada nave se distribuye una plétora de microcosmos virtuales - una aldea africana, una ciudad estadounidense del siglo XX, un castillo medieval, un mundo nuevo, sin referente real- percibidos por la población gracias a unos implantes de realidad aumentada. Los individuos moran en el microcosmos deseado a cambio de acatar sus normas, estéticas y costumbres. Y es que la vida en las naves antorcha es ociosa, liberal, hedonista, pacifista, snob. La tecnología de los "tubos de propulsión" garantiza la mayor de las abundancias. Pero el bienestar proporcionado por los mundos sintéticos no sofoca el deseo colectivo de encontrar un hogar natural. A esa tarea se encomiendan los "sorbevacíos", especialistas en escrutar el universo. Jofe D'mahl destapará el secreto que guardan celosamente: que no existe en el cosmos ningún planeta habitable. Lejos de desesperarse frente a la ausencia terminante de naturaleza, D'mahl empuña una exaltación antropocéntrica del artificio:

Hemos contemplado lo que no ha sido hecho por nosotros, y lo hemos hallado desprovisto de vida y significado, y por completo insuficiente... Abandonaremos las cosas de la infancia: dioses y demonios, soles y planetas, culpas y lamentaciones... ¿No vamos a decir: crezcamos y multipliquémosnos y llenemos las muertas e infinitas extensiones del vacío con naves, y vida, y significado? ${ }^{82}$.

Terraformar la Tierra y Jinetes en la antorcha valen como metáforas de la condición postmoderna (un mundo sin naturaleza) y de dos disposiciones perseverantes. La primera deja constancia de la creación de la naturaleza-artificial y del descrédito de los dualismos naturalistas tradicionales, la segunda de la nostalgia que lo natural suscita una vez destruido y deconstruido. Pero será la robusta "Trilogía de Marte" de Kim Stanley Robinson quien mejor especule sobre las problemáticas aludidas. El relato empieza a mediados del siglo XXI, con el planeta Tierra a merced del capitalismo mundializado, de las guerras locales y la miseria, golpeado por los efectos devastadores de un cambio climático descontrolado y a medio plazo letal para la supervivencia humana. Dado el panorama, cien científicos e ingenieros procedentes de naciones diversas son enviados a Marte con la intención de volverlo habitable para los hombres y rentable para las multinacionales. Lo que nadie preveía es que esas personas no se limitarán a sentar las directrices de la creación de la naturaleza. Víctimas en primera persona de la dinámica ecocida del capitalismo, se negarán a replicarlo y plantarán las semillas de un régimen político-económico alternativo, apto para vérselas con el medioambiente sin destruirlo. La llegada progresiva de millones de colonos derivará en una guerra a gran escala entre los partidarios de la revolución y los servidores de las multinacionales.

Los conflictos aparecerán muy pronto entre los "Primeros Cien". Un grupo considerable se unirá contra la alteración del hábitat original marciano, dando lugar a un movimiento ecologista armado ("los rojos") al que se sumarán decenas de miles de inmigrantes posteriores. Su posicionamiento conservacionista y romántico en favor de la no manipulación de Marte se irá moderando a medida que avance el relato, al igual que el de los defensores de la terraformación (los "verdes"). En su versión inicial, la mentalidad roja es expresada por Ann, una suerte de gemelo postmoderno del utopista rural de siempre: "Esta carretera que hemos hecho, ¡me duele verla! Y

82 N. Spinrad, Jinetes de la antorcha, Barcelona, Ediciones B, 1987, pp. 129-130. 
el campamento base es como el pozo abierto de una mina, en medio de un desierto que no ha sido tocado nunca desde el comienzo del tiempo... No quiero hacerle eso a Marte... Preferiría morir. Dejemos el planeta en paz, dejemos su soledad"83. Sax, partidario de la terraformación integral, le responde blandiendo los lemas del humanismo utópico urbano:

La belleza de Marte existe en el espíritu humano... Sin la presencia humana es sólo una acumulación de átomos... Somos nosotros quienes lo entendemos, y nosotros quienes le damos sentido... Podemos transformar Marte y construirlo como si levantáramos una catedral, un monumento tanto a la humanidad como al universo. Podemos hacerlo, así que lo haremos ${ }^{84}$.

Las implicaciones ontológicas latentes a la disputa entre rojos y verdes son iluminadas con tino por Jürgen:

Los dos bandos dicen que están a favor de la naturaleza. Los rojos afirman que el Marte que ya está aquí es la naturaleza. Pero no es la naturaleza, porque está muerto... Los verdes dicen que traerán la naturaleza a Marte con la terraformación. Pero eso tampoco es naturaleza, sólo es cultura. Ya sabe, un jardín. Una obra de arte. De modo que ninguno de los dos tiene lo que quiere. No hay naturaleza en Marte ${ }^{85}$.

Hiroko encarna la ortodoxia deconstruccionista que ya conocemos y resuelve que Marte "no es ni naturaleza ni cultura"

En el nivel político, la catástrofe ecológica de la Tierra provoca que los rebeldes rehúsen estructurar su proyecto emancipatorio alrededor de la ideología, tan bien avenida con el capitalismo, del desarrollo sostenible y que decidan desarrollar "una prosperidad sostenible para la entera biosfera"87. A partir de esta máxima, materializada en una terraformación sutil, gradual y localizada, las heterogéneas facciones revolucionarias acuerdan tras intensas discusiones que los "cambios medioambientales han de ser... mínimos y ecopoyéticos" $"$, practicados por debajo de los cuatro mil metros de altitud. Art remacha los "puntos de trabajo para un gobierno marciano" presentados ante la muchedumbre con las siguientes consideraciones:

La colonización del planeta Marte es un proceso histórico único... Como tal, debe ser emprendida con un espíritu de reverencia hacia este planeta y hacia la rareza de la vida en el universo. Lo que hagamos aquí sentará los precedentes para la futura habitación humana del sistema solar, y sugerirá asimismo modelos de relación del hombre con el medioambiente de la Tierra ${ }^{89}$.

\footnotetext{
83 K. S. Robinson, Marte rojo, Barcelona, Minotauro, 1997, p. 168.

84 Ibidem, p. 187-188.

85 Ibidem, p. 271.

86 Ibidem, p. 387.

87 K. S. Robinson, Marte verde, Barcelona, Minotauro, 1997, p. 413.

88 Ibidem.

89 Ibidem.
} 


\section{A modo de conclusión: Trascender a la naturaleza}

Nuestro análisis ratifica tres lances: i) La indiferencia de la utopía moderna estándar — quizás por negligencia, quizás por puro desconocimiento — ante los impactos medioambientales nocivos ocasionados por el dominio y perfeccionamiento de la naturaleza: ii) El surgimiento, encaminado a contrarrestar el influjo del modus operandi del hombre primero, de utopías del campo y distopías liberales trabadas hasta mediados del siglo XX al ideal romántico de reconciliación con la Madre Naturaleza y anexionadas desde los prolegómenos de la postmodernidad a un ecologismo consciente y militante: iii) La convergencia de todas las escuelas utópicas enumeradas a los pies de la naturaleza-natural, sea para mancillarla y clamar por su dominio y perfeccionamiento, sea para exaltarla y clamar por su salvaguarda, conservación o restauración.

En el último apartado hemos expuesto cómo operando una radicalización premeditada de las propensiones constructivistas adjuntas a algunas utopías estándar de la modernidad, la utopía estándar de la postmodernidad se distingue de los modelos utópicos anteriores por negar la existencia de la naturaleza-natural. Aboga, grosso modo, por la creación de una naturaleza-artificial a partir de parámetros medioambientalmente comprometidos que amonestan con efecto retroactivo la indiferencia ecológica ostentada por Wells, Cabet y el resto de baconianos duros sin demonizar a la tecnología y sin renunciar al humanismo, a la autodeterminación y a la fe en el progreso. La saga marciana de Kim Stanley Robinson ejerce una crítica utopista a la utopía sumamente iluminadora en este sentido. Enseña, por de pronto, que esperanza y responsabilidad no son incompatibles, que la acción tecnológica del hombre primario y la civilización altamente avanzada que lo acoge pueden convivir con el cuidado del entorno físico. No hay, viene a añadir, ninguna imposibilidad metafísica o esencia malévola de la tecnología que lo impida y haga de las invitaciones ruralistas a recogernos junto a la hoguera de la aldea bucólica la única alternativa. Hay, a lo sumo, dificultades políticas concernientes al tipo de poder que dirige el mundo y emplea los dispositivos técnicos. Robinson defiende que los problemas ecológicos solo serán convenientemente abordados y solventados de alguna manera en el marco de un régimen económico diferente al imperante. A fin de cuentas, es el modelo productivo vigente quien degrada los ecosistemas y quien continuará haciéndolo hasta el final si nada se le opone. De la "Trilogía de Marte" se infiere la certeza de que la agresión medioambiental proviene de la lógica del crecimiento ilimitado, la producción infinita y el consumismo desaforado adjunta al conjunto de la civilización tiempo ha. Tal vez Jonas esté en lo cierto y bajo esa lógica lata un impulso utópico. Nosotros creemos necesario matizar en honor de la verdad que late, más bien, un impulso que fue utópico en principio y que asimilado por el statu quo dejó de serlo en sentido estricto para convertirse en ideológico y obstaculizar la emancipación. En cualquier caso, sería absurdo negar que la utopía estándar de la modernidad rebosa de contraindicaciones y contradicciones en multitud de áreas. Tantas, la tocante a la naturaleza es solo una de ellas, que la única expectativa razonable para quienes todavía sueñan con un futuro mejor pasa por idear una utopía urbana mejor.

Antes de terminar, nos atrevemos a dirigir unas reflexiones finales a los escritores y pensadores utópicos de la actualidad que se sientan tentados de restaurar normativa y ontológicamente a la naturaleza-natural. Jürgen, personaje de Marte Rojo, sentenciaba hace apenas unas páginas que "no hay naturaleza en Marte". Ni falta 
que hace. Los rebeldes no van a repetir los errores del pasado y elevan a imperativo el cuidado del entorno biofísico que ellos mismos están creando. Entre líneas, la saga de Robinson murmura si se adopta cierto sesgo hermenéutico las directrices de una utopía urbana con conciencia medioambientalista situada más allá del término y de la nostalgia de naturaleza. La insinuación conecta con el construccionismo pragmatista y materialista de Steven Vogel, resuelto a diseñar "una teoría acerca del carácter ontológico y normativo de nuestras relaciones con el medioambiente... que no emplee el concepto de naturaleza" ${ }^{90}$. ¿Por qué no hacerlo? Primero, porque como bien argumentó McKibben la naturaleza ha muerto materialmente. Segundo, porque el concepto de "naturaleza" resulta, siendo generosos, ambiguo (¿qué denota en realidad?) y, lo que es peor, peligroso, cargado de connotaciones metafísicas y axiológicas, tendente a suscitar la estampa de una otredad radicada fuera de la sociedad ante la que los humanos deben plegarse si quieren sortear el castigo apocalíptico. Justo, dice Vogel, porque nos preocupa el cambio climático, la mengua de la biodiversidad y el agujero de la capa de ozono haríamos bien en abandonar la idea de naturaleza - glorificada por el capitalismo y sus secuaces - y adoptar en su lugar la de "medioambiente" u otra similar. El cambio lleva implícito que el mundo jamás fue puro, que siempre fue, para bien y para mal, creado y transformado por prácticas humanas variables y contingentes, el fruto de la negociación y el disenso, y que justo por ese motivo carece de sentido distinguir entre lo social y lo natural, como si hubiera dos mundos y no uno solo; el mundo en cuya configuración estamos activamente inmersos. El cambio lleva implícito del mismo modo que las cuestiones ecológicas son cuestiones políticas que han de afrontarse políticamente, a los pies de los criterios derivados de las prácticas citadas, no — como ha sido lo habitual- de la noción esencialista de naturaleza que eclipsa la politización de las controversias y la adopción de remedios alternativos. Ello significa que si el medioambiente presenta señales preocupantes hemos de modificar las prácticas hegemónicas, incluso canjearlas por otras, no elaborar el enésimo informe científico o celebrar la enésima Cumbre cegados por el mito de la sostenibilidad, deficitario de la figura fantasmática de una naturaleza original que hemos alterado. Mientras se nos impele abiertamente a cambiar nuestra conducta voraz ante la naturaleza, se nos obliga subrepticiamente a aceptar que política y económicamente todo seguirá igual en el futuro ${ }^{91}$. La utopía renovada surge para cortocircuitar esta maniobra ideológica.

$90 \quad$ S. Vogel, "Environmental Philosophy after the End of Nature", Environmental Ethics, 24, 2002, p. 28.

91 Ibidem, p. 35. Vogel replica a los potenciales acusadores. Su propuesta, afirma, no peca de idealista, dado que el agente constructor del mundo no es el discurso, sino las prácticas humanas. Tampoco de relativista, dado que las prácticas que reconocen nuestra responsabilidad causal y moral en el destino del mundo son preferibles a aquellas que la ocultan o que la asignan a las actitudes de individuos aislados. Ibidem, pp. 33-37. 